\title{
TESTING AND NUMERICAL ANALYSIS ON COLD-FORMED STEEL SHEAR WALLS USING CORRUGATED STEEL SHEATHING
}

\author{
Wenying Zhang*, Yuanqi Li*, Cheng Yu** \\ * Tongji University, Shanghai, 20092 \\ e-mails: WenyingChangan@163.com, liyq@tongji.edu.cn \\ ** University of North Texas \\ e-mail: Cheng.Yu@unt.edu
}

\begin{abstract}
Cold-formed steel framed shear wall sheathed with corrugated steel sheets is a promising shear wall system for low- and mid-rise constructions at high wind and seismic zones due to its advantages of non-combustibility, high shear strength, and high shear stiffness. Monotonic and cyclic tests on full-scale wall assemblies using corrugated steel sheathing was conducted. To investigate the effect of vertical/gravity loading, shear wall specimens were tested under two different loading conditions: lateral loading, and a combined lateral and vertical/gravity loading. The test results are presented and discussed in this paper. Besides, finite element model of the proposed shear wall was created in Abaqus software. The validity of the numerical model was verified based on the test results. A series of parametric analysis were conducted, including the thickness of framing members, the cross section of stud members, yield strength of the frame members, stud spacing, and the influence of gravity loads. The detailed modeling information, relevant parametric analysis and recommendations for practical application of this type of shear resisting system are also presented.
\end{abstract}

Keywords: Cold-formed steel shear walls, Corrugated steel sheathing, Testing, Numerical analysis.

\section{INTRODUCTION}

The cold-formed steel (CFS) corrugated sheet has been widely used in the floor diaphragms and roof decks in both residential and commercial buildings. The CFS corrugated steel sheets usually have considerably high in-plane strength and stiffness due to its cross-section shape. When designed properly, CFS shear wall sheathed with corrugated sheets could be used as an alternative lateral-force resisting system. Some studies have been done to investigate the behavior of CFS corrugated sheet shear walls. Fülöp and Dubina (2004) conducted a testing project to study the structural performance of $2.44 \mathrm{~m}$ high, $3.66 \mathrm{~m}$ wide CFS shear walls using three different sheathing materials: LTP20/0.5 corrugated steel sheet, gypsum boards, and oriented strand boards (OSB). A total of 7 monotonic 8 cyclic shear wall tests were performed in their project and Fülöp and Dubina (2004) concluded that the CFS walls with corrugated sheets behaved like a rigid board and the shear wall configuration could provide lateral-force resistance effectively. They witnessed failures of the seam fasteners in corrugated sheet specimens which resulted in a desired ductile behavior of the entire shear wall assembly.

Stojadinovic and Tipping (2007) conducted a series of 44 cyclic shear wall tests on $2.49 \mathrm{~m}$ high $\times$ $1.22 \mathrm{~m}$ or $0.61 \mathrm{~m}$ wide CFS shear walls with single sided and double sided corrugated steel sheathing. The corrugated sheets were $0.686 \mathrm{~mm}, 0.838 \mathrm{~mm}$, and $1.092 \mathrm{~mm}$ Shallow-Verco type decking with 14.3 $\mathrm{mm}$ rib height. The shear wall's framing members were varied from $0.838 \mathrm{~mm}$ to $1.727 \mathrm{~mm}$ in thickness. The test program also included No. 10,12, and 14 self-drilling screws and pins as various parameters in the shear wall configurations. However different than the standard CFS shear wall design, the boundary elements of all the shear walls tested in Stojadinovic and Tipping (2007) were reinforced by hot-rolled steel HSS $152 \mathrm{~mm} \times 102 \mathrm{~mm} \times 9.5 \mathrm{~mm}$ sections which excluded failures in the boundary elements and 
required no hold-down to be installed. Stojadinovic and Tipping (2007) reported that in all the tests, the failure mode was the eventual pulling out of the screws due to warping in the corrugated steel sheet.

In order to address the issues in previous research and study a boarder range of configuration variations, Yu et al. (2009) and $\mathrm{Yu}$ (2013) conducted a series of full scale monotonic and cyclic tests at the University of North Texas (UNT). The test program at UNT focused on standard CFS framing details with low-profile corrugated sheet sheathing and test methods recommended by the International Code Council (www.iccsafe.org) were adopted. The test results concluded that the CFS framed shear walls using corrugated steel sheathings yielded higher strength, greater initial stiffness, and similar ductility under cyclic loading when compared with the CFS walls using conventional sheathing materials: flat steel sheets, plywood panels, and OSB.

Currently, most shear walls are designed through empirical methods derived directly from full scale tests, which is time-consuming and costly. Numerical simulations, as a substitutable method, allow the researchers to study the performance of these walls, and to share discoveries with designers. Dai (2012) created a FE model of typical wall-stud cold-formed steel wall panels under monotonic loading. The influences of sheath sheeting, connectors and fixing boundary conditions on the structural behavior of selected wall panels were investigated. An extensive study was completed by Hung Huy Ngo (2014) at John Hopkins University to develop a high fidelity computational model of wood-sheathed CFS framed shear walls. Sufficient progress has been made on component to system-level simulations though previous computational modeling has been on OSB and flat steel sheets without the introduction of perforations.

Results of the previous researches indicated that corrugated steel sheet sheathing was a feasible solution for CFS shear walls. However, all these previous investigations have focused on the performance of shear walls under lateral loading only. In the actual light frame CFS buildings, the shear walls are usually subjected to both lateral and vertical loads. To observe the performance of the corrugated steel sheathing shear walls under combined lateral and vertical/gravity loading and to determine the effect of vertical/gravity loading, monotonic and cyclic tests on full-scale wall assemblies using corrugated steel sheathing were conducted under two different loading conditions: lateral loading, and a combined lateral and vertical/gravity loading. Besides, finite element model of corrugated steel sheathing shear walls was created in Abaqus software (2014) and validated to the test results. A series of parametric analysis were also conducted and recommendations for practical application of this kind of wall were proposed.

\section{TEST PROGRAM}

\subsection{Test Specimens}

The test program included a total of 5 wall specimens: 3 monotonic and 2 cyclic. In order to investigate the influence of gravity loading, two of the wall specimens were tested under only lateral loading. The details of the labeling and description of the test specimens are presented in Table 1. All wall specimens in this research were $2.44 \mathrm{~m}(8 \mathrm{ft})$ high, $1.22 \mathrm{~m} \mathrm{(4ft)}$ wide with an aspect ratio of 2:1. The framing members used Steel Studs Manufacturers Association (SSMA) structural stud 350S200-68 (345 Mpa) and track 350T150-68 (345 Mpa). Double C-shaped sections were used for the chord/boundary studs and one $\mathrm{C}$-shaped section for the vertical field stud. Two hold-downs and two shear bolts were used to secure the shear wall specimens to the test bed. For each wall, the sheathing consisted of three Shallow Verco Decking SV36 corrugated steel sheets with $0.686 \mathrm{~mm}$ (27 mil) thickness and 14.3 $\mathrm{mm}(9 / 16 \mathrm{in}$.) rib height. Due to the metal sheathing profile, the spacing of the screws were limited to $76.2 \mathrm{~mm}(3 \mathrm{in}$.) module at the horizontal seams of the sheets, $76.2 \mathrm{~mm}(3 \mathrm{in}$.) along the perimeter and $152.4 \mathrm{~mm}(6 \mathrm{in}$.$) along the interior stud. Figure 1$ shows the details of the wall configuration. 


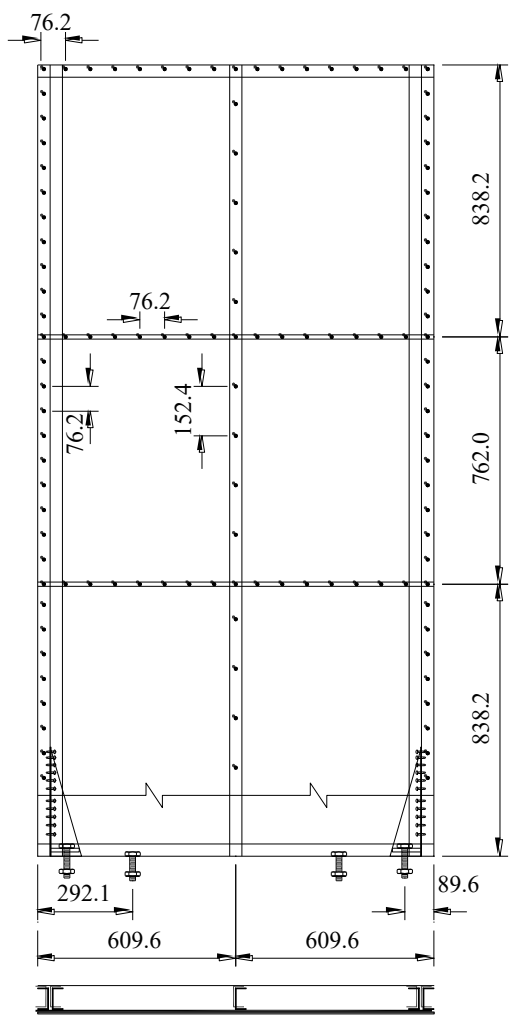

Figure 1: Schematic Drawing of Shear Wall Configuration

Table 1: Matrix of test wall specimens

\begin{tabular}{|c|c|c|}
\hline Label & Loading protocol ${ }^{\mathrm{a}}$ & $\begin{array}{l}\text { Gravity } \\
\text { loading }\end{array}$ \\
\hline SW-M1 & M & Yes \\
\hline SW-M2 & M & Yes \\
\hline SW-M3 ${ }^{\mathrm{a}}$ & M & No \\
\hline SW-C1 & $\mathrm{C}$ & Yes \\
\hline $\mathrm{SW}-\mathrm{C} 2^{\mathrm{a}}$ & $\mathrm{C}$ & No \\
\hline
\end{tabular}

Note: b. M-Monotonic loading, C-Cyclic loading.

\subsection{Test Setup}

All the tests were conducted using a $156 \mathrm{kN}$ (35 kip) hydraulic actuator and a 4.88 meter (16 ft.) span, 3.66 meter (12 ft.) high equilibrium steel testing framing. Specimens were secured to the test bed and lateral fore was applied to the wall horizontally on the top track through a loading beam. Applied force was measured using an $89 \mathrm{kN}$ (20 kip) load cell placing between the actuator shaft and the loading beam. The loading beam was connected to the top track of the wall by No.12 self-drilling screws. The out-ofplane movement of the specimen was controlled by the lateral supports located at the top of the testing frame on both sides of the loading beam. A total of five position transducers were used in this test setup in order to measure the displacement of each specimen at the following locations: horizontal 
displacement at the top of the wall, the vertical and horizontal displacements at the bottom of the two boundary studs.

The gravity loading system consisted of two weight boxes and a frame to prevent the weight boxes from contacting the wall specimens during testing. The weight boxes, filled with sand bags, were suspended from the loading beam by steel chains. The applied gravity load was estimated from a typical 2-story office building in the NEES-CFS project (Madsen, Nakata, Schafer, 2011). The gravity load was calculated as the sum of the dead load and $25 \%$ of the live load. Test setup of the combined lateral and gravity loading system are shown in Figure 2.

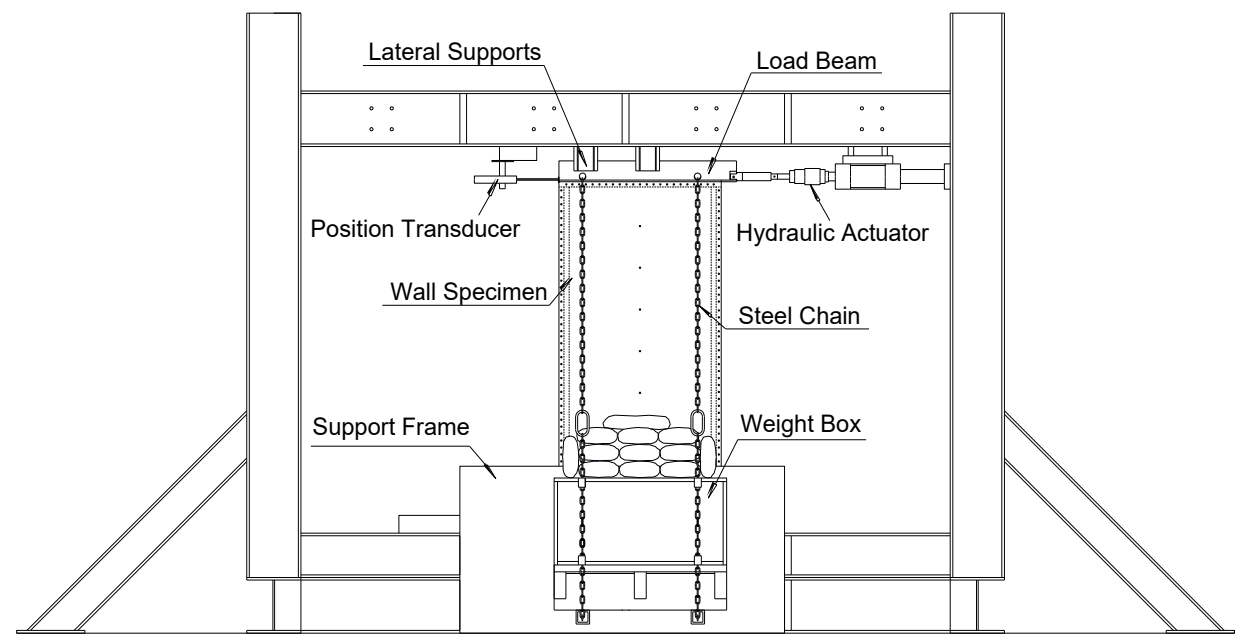

Figure 2: Front view of the test setup

\subsection{Test Procedure}

The procedure of the monotonic tests was in accordance with ASTM E564 (2012) "Standard Practice for Static Load Test for Shear Resistance of Framed Walls for Buildings". A uniform loading rate of $0.191 \mathrm{~mm} / \mathrm{s}(0.0075 \mathrm{in} . / \mathrm{sec})$ was applied to the loading beam. The cyclic tests followed the method $\mathrm{C}$ in ASTM E2126 (2012) "Standard Test Methods for Cyclic (Reversed) Load Test for Shear Resistance of Vertical Elements of the Lateral Force Resisting Systems for Buildings". The standard CUREE loading history includes 40 cycles with specific displacement amplitudes. This test program used 43 cycles in order to fully investigate post peak behavior of the walls. For the combined lateral and gravity loading tests, the gravity load was applied to the wall specimens prior to the lateral loading and the gravity load remained constant during the test. The lateral load was then applied to the top of the wall using displacement based protocols.

\subsection{Material Properties}

Coupon tests are conducted according to the ASTM A370 (2006) "Standard Test Methods and Definitions for Mechanical Testing of Steel Products" to obtain the actual properties of the test materials. The coatings on the steel samples were removed by hydrochloric acid before testing. A total of three coupons were tested for each member, and the average values are listed in Table 2. 
Table 2: Material properties

\begin{tabular}{lcccc}
\hline \multicolumn{1}{c}{ Member } & $\begin{array}{c}\text { Uncoated } \\
\text { Thicknes } \\
\mathrm{s}\end{array}$ & $\begin{array}{c}\mathrm{Fy} \\
(\mathrm{Mpa})\end{array}$ & $\begin{array}{c}\mathrm{Fu} \\
(\mathrm{Mpa})\end{array}$ & $\begin{array}{c}\text { Elongation } \\
\text { for 50mm } \\
\text { Length } \\
(\%)\end{array}$ \\
\hline $345 \mathrm{Mpa}, 1.727 \mathrm{~mm}$ track & 1.788 & 391.6 & 497.8 & 14.1 \\
$345 \mathrm{Mpa}, 1.727 \mathrm{~mm}$ stud & 1.801 & 379.2 & 490.2 & 29.8 \\
$550 \mathrm{Mpa}, 0.686 \mathrm{~mm}$ sheet & 0.752 & 593.6 & 619.8 & 3.9 \\
\hline
\end{tabular}

\subsection{Test Results}

\subsubsection{Failure modes}

Despite of gravity load, all the shear wall specimens demonstrated the same failure mechanical under monotonic loading. The observed failure modes were the shear buckling of the corrugated sheet and screw pulling over sheathing at boundary studs. By the end of the loading protocol, an obvious diagonal tension field at the bottom sheet was formed and twisting of the chord studs was observed. The deformation of shear wall specimens under monotonic loading is shown in Figure 3. The shear wall specimens exhibited similar failure mechanism under cyclic loading. The failure modes were the shear buckling of the corrugated sheet and screw pulling over of bottom sheathing. Ultimately, two opposing tension fields formed and local buckling occurred on the chord studs. The deformation of shear wall specimens under cyclic loading is shown in Figure 4.

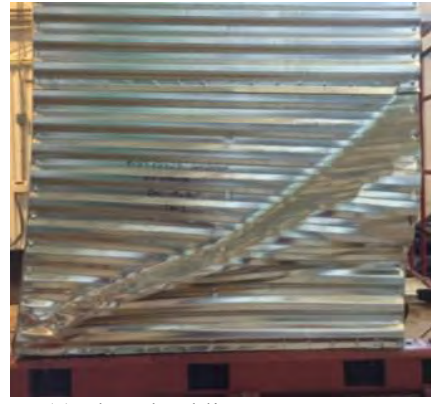

(a) Sheet buckling

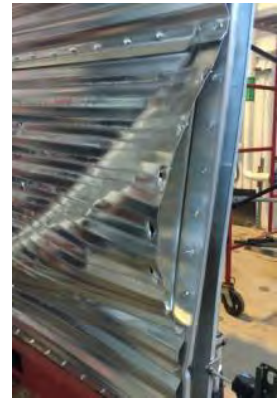

(b) Screw pulling over

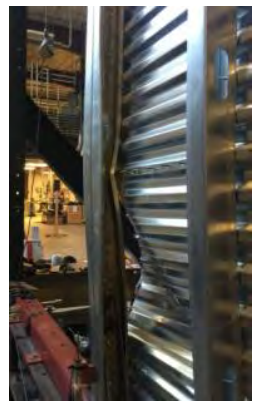

(c) Stud buckling

Figure 3: Observed Failure Modes of Shear Wall under Monotonic Lateral Loading
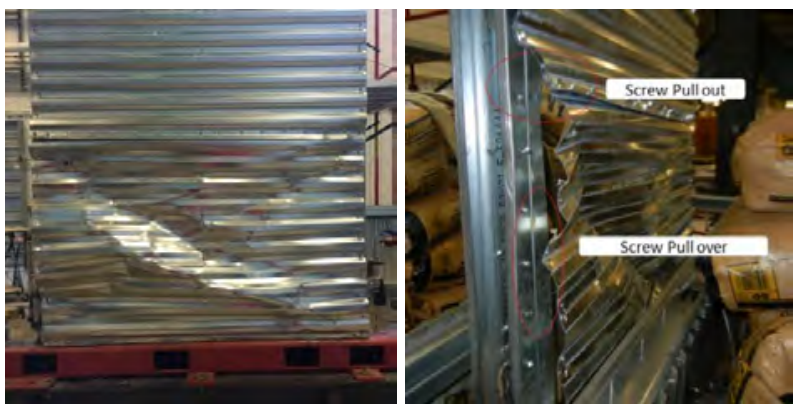

(a) Sheet buckling and tension field development (b) Screw failure

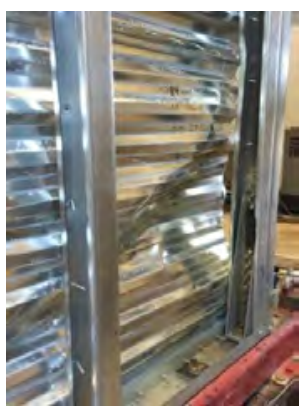

(c) Stud buckled

Figure 4: Failure mode of shear wall under cyclic loading 


\subsubsection{Measured Wall Properties}

The performance parameters obtained from each wall specimen are provided respectively in Table 3 . Ductility factor was calculated using the equivalent energy elastic plastic model (EEEP) according to AISI S240 (2012). The results include the test peak load, $\mathrm{P}_{\max }$, lateral displacement at peak load, $\Delta_{\max }$, initial stiffness, K, the ductility factor, as well as dissipated energy. For the hysteresis curve, backbone curves in both the positive and negative displacement regions were first identified by plotting locus of all the peak force points at the first cycle of the same displacement amplitude cycles. Then the parameters were determined from the back-bone curves. Dissipated energy was defined as the area under the backbone curve.

Table 3: Test results

\begin{tabular}{cccccc}
\hline Specimen & $\begin{array}{c}\mathrm{P}_{\max } \\
(\mathrm{kN})\end{array}$ & $\begin{array}{c}\Delta_{\max } \\
(\mathrm{mm})\end{array}$ & $\begin{array}{c}\mathrm{K} \\
(\mathrm{kN} / \mathrm{m} .)\end{array}$ & $\begin{array}{c}\text { Ductilit } \\
\mathrm{y} \\
\text { factor }\end{array}$ & $\begin{array}{c}\text { Energ } \\
\mathrm{y} \\
(\mathrm{J} / \mathrm{m})\end{array}$ \\
\hline SW-M1 & 83.76 & 68.6 & 2064 & 2.12 & 3385 \\
SW-M2 & 83.27 & 64.5 & 1970 & 1.80 & 2975 \\
SW-M3 $^{\mathrm{a}}$ & 80.83 & 68.4 & 2165 & 2.19 & 3066 \\
SW-C1 & 76.14 & 62.7 & 1929 & 2.61 & 4072 \\
SW-C2 $^{\mathrm{a}}$ & 78.75 & 68.0 & 1646 & 2.21 & 4115 \\
\hline
\end{tabular}

\subsubsection{Discussion of Test Results}

In reviewing the test results, it is important to note that the objectives of the tests reported here are to observe the performance of shear walls under combined lateral and gravity loading, and to identify the influence of gravity loads. Firstly, identical specimens were compared under monotonic loading and cyclic loading. Figure 5 shows the comparison of loads vs. displacement curves of monotonic loading and cyclic loading. According to Table 3, the average absolute of the positive and negative peaks from the backbone curves were $91 \%$ and $97 \%$ of the ultimate strength from the monotonic curves for combined loading and lateral loading, respectively. This indicates the extent of the strength degradation in the cyclic loading protocol.

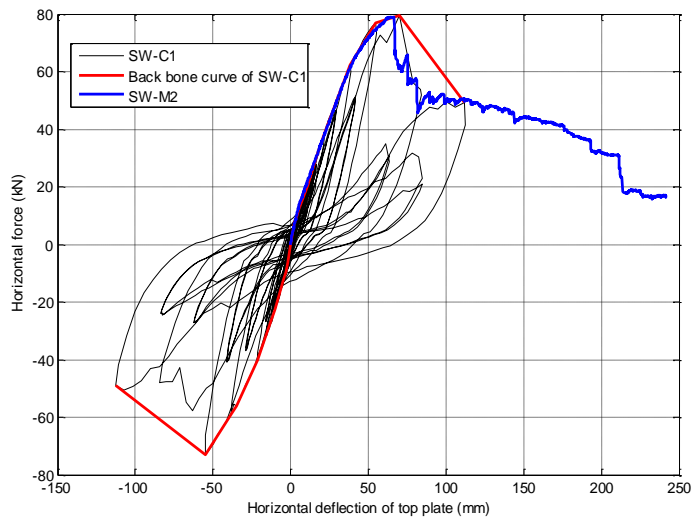

Figure 5: Comparison of monotonic loading and cyclic loading

The impact of the gravity loads was of great interest to this research. Therefore a comparison was made between SW-C1 specimen and SW-C2 specimen to observe the impact of gravity loads explicitly. The comparisons of the loads vs. displacement curves are shown in Figure 6. The following conclusions can be made according to Figure 6 and Table 3: gravity load at the service load level seems make no difference on the shear walls' lateral behavior. The shear strength, initial stiffness as well as displacement at peak load were all remained at the same level. 

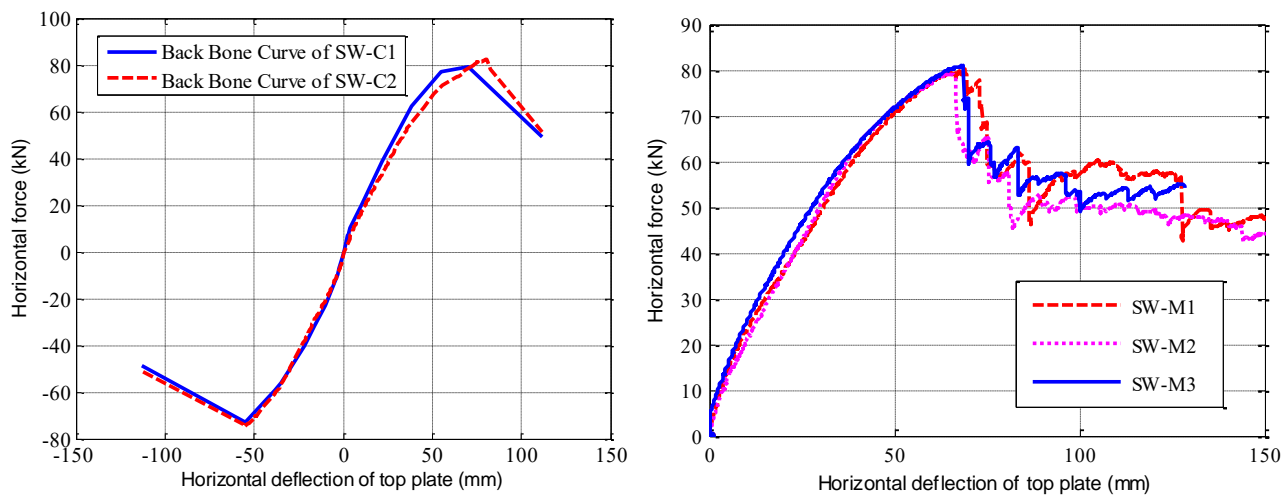

Figure 6: Influence of gravity loading

\section{FINITE ELEMENT ANALYSIS (FEA)}

\subsection{Modeling Technique}

\subsubsection{Components \& Geometry}

The dimensions and thicknesses of each shear wall components were from the Steel Stud Manufacturers Association product technical guide (SSMA 2015). The profile dimensions of the corrugated sheathings were in accordance with those provided by Verco Decking. It should be pointed out that the top and bottom tracks were modeled $2 \mathrm{~mm}(0.08 \mathrm{in}$.) wider so the studs would fit within the tracks without penetration. All components were modeled using 4-node homogeneous shell elements, type S4R, in Abaqus. The mesh size of the framing members used $12.7 \mathrm{~mm}(0.5 \mathrm{in}$.) and $38.1 \mathrm{~mm}(1.5 \mathrm{in}$.) for the corrugated sheets.

\subsubsection{Material Properties}

Bilinear Isotropic material properties were used for both framing members and corrugated sheathings. The Young's modulus was set as $201,000 \mathrm{Mpa}(29,500 \mathrm{ksi})$ and Poisson's ratio was 0.3 . The modulus of the second phase was set as $1 / 100$ of the elastic modulus, which was based on the coupon test results in Mahdavian et al. (2016). Nominal yield strength was used for all elements in this research.

\subsubsection{Interaction}

Since no framing connection failure occurred in all the tests, tie constraints were used for stud-to-stud and stud-to-track connections. It is important to mention, members selected as master or slave are of great significance in finite element analysis. Figure 7 shows the tie constraints of the stud-to-track and stud-tostud connections.

\subsubsection{Boundary Conditions}

All the nodes on the web of the bottom track as well as the bottom edges of the studs are restrained in all three directions following the test setup. Two lines of nodes on the web of the top track were restricted against the translation toward the out-of-plane direction in order to simulate the lateral support, shown in Figure 8. Also, the vertical direction of all the nodes at the hold-down area of each chord stud is restrained, as shown in Figure 8. 


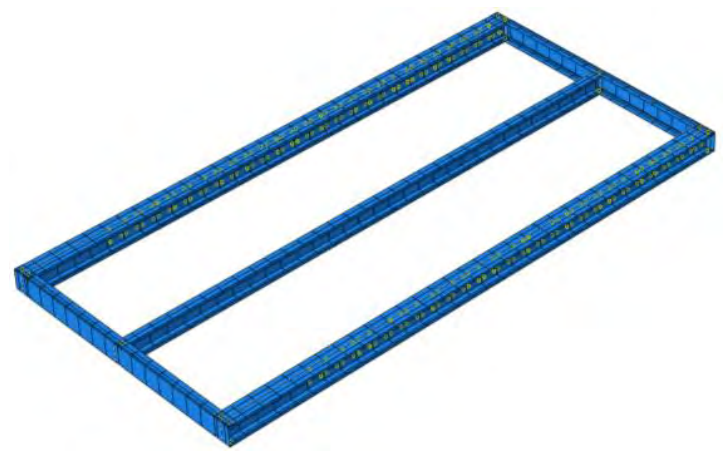

Figure 7: Framing tie constraints
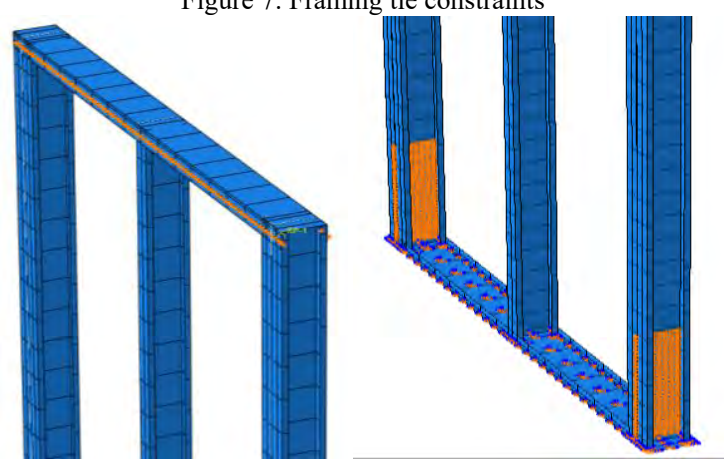

Figure 8: Boundary Conditions(a) Out-of-plane restraint (b)Bottom and Hold-down restraint

\subsubsection{Contact Properties}

A contact property was introduced between the surfaces of the corrugated sheathing and the studs to prevent the sheathing from penetrating through the framing members. A "frictionless tangent" behavior and "hard-contact normal" behavior were defined at these locations. The contact locations can be seen in Figure 9.
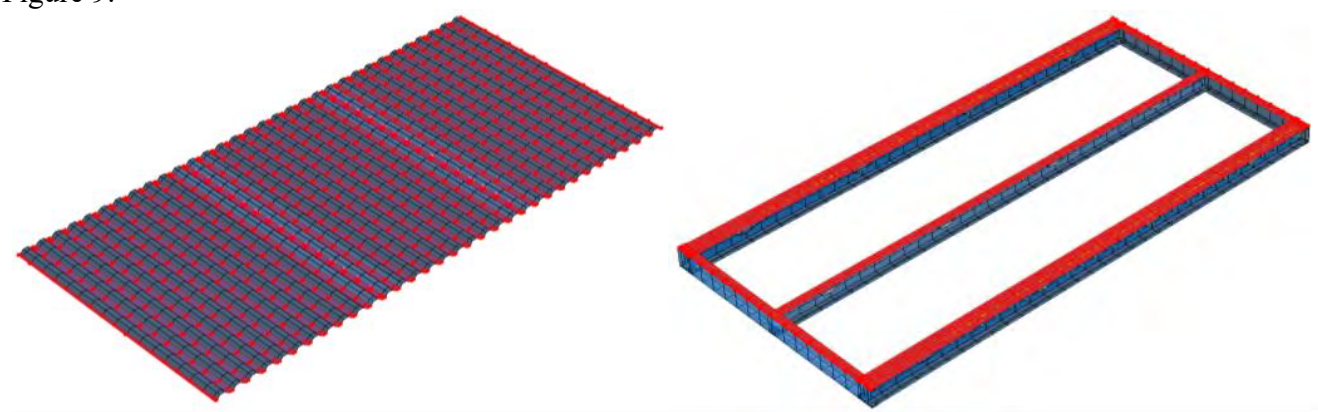

Figure 9: Contact surface locations

\subsubsection{Sheathing Connections}

The sheathing-to-frame and sheathing-to-sheathing screws were simulated by spring2 elements in Abaqus. This type of spring defines an element between 2 nodes acting in a fixed direction. Each screw 
connection was modeled by 3 spring elements, one withdrawal spring and two shear springs. The spring stiffness was based on connection test results. The simulation of the spring connections is shown in Figure 10.

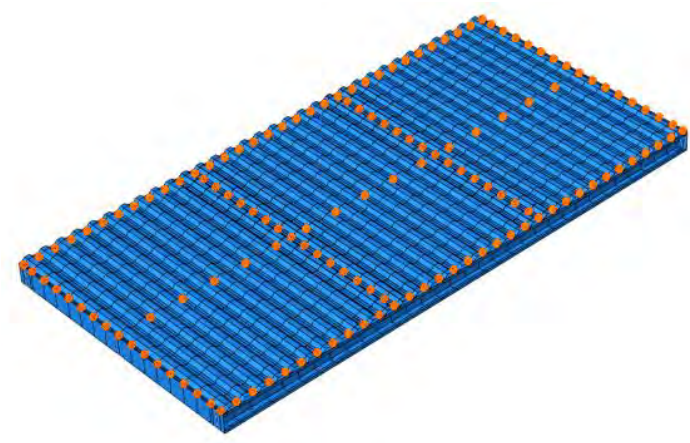

Figure 10: Spring connections

\subsubsection{Loading Method}

According to the test results, gravity load seems make no difference on the shear walls' lateral behavior. Therefore only lateral loading was applied in the FE analysis. All the nodes on the web of top track were coupled to a reference point located on the edge of the top track, as depicted in Figure 11. A displacement controlled lateral load was applied to the reference point along the horizontal direction.

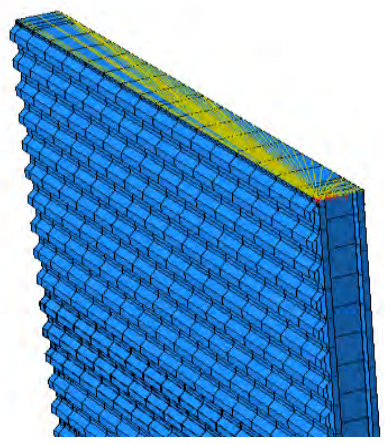

Figure 11: Loading method

\subsection{Simulation Results}

To verify the validity of the finite element model, the FEA results were compared with test results of SW-M3 numerically as well as in terms of deformation and performance. The load-displacement responses are illustrated in Figure 12 and the comparison of the characteristic values is shown in Table 4. The Abaqus model was able to match the shear wall behavior well prior to the peak load. The initial stiffness of the Abaqus model is comparable to the full scale test initial stiffness. The displacement at the peak load determined from the test differs somewhat from that obtained by FEA, and the difference reaches $14 \%$. However, the shear capacities are almost the same, which validates the accuracy of the FE model. In the full scale test, the shear wall tested failed due to shear buckling of the bottom sheet which led to the screw pull-over failure at the sheet-to-stud connections. In Abaqus, the initial failure observed was the buckling of the corrugated sheet. Stress distribution was mainly focused on the bottom 
corrugated sheet which was in accordance to the full scale test results. In the test, the second loss of strength was caused by the local buckling and distortional of the chord studs. A slight torsional and local buckling of the chord stud was also noticed in the model. The comparisons of the failure modes are shown in Figure 13.

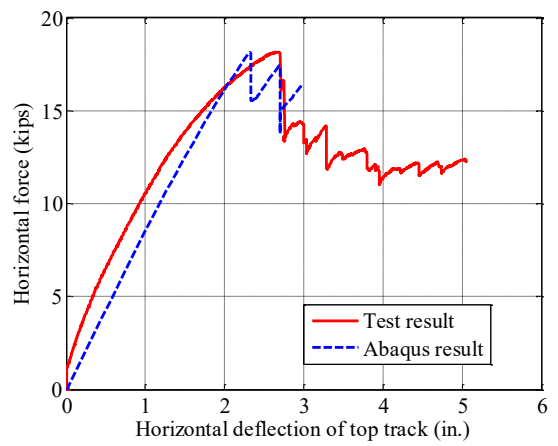

Figure 12: Load vs. displacement responses
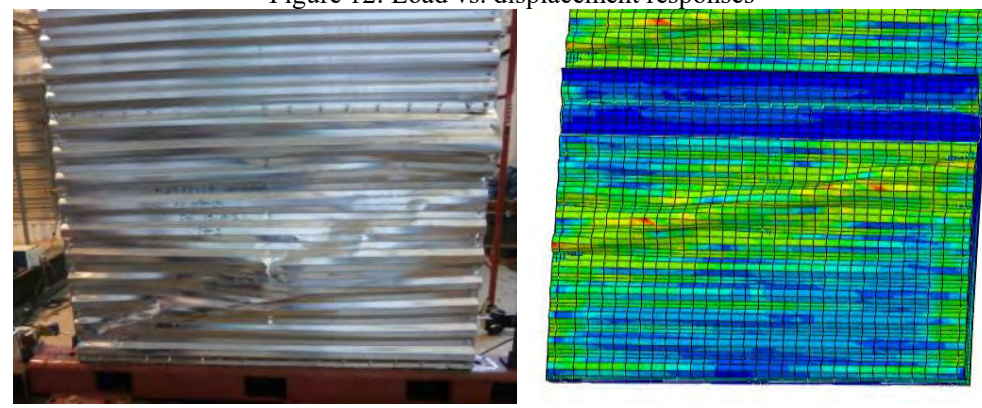

(a) Stress distribution on bottom sheet
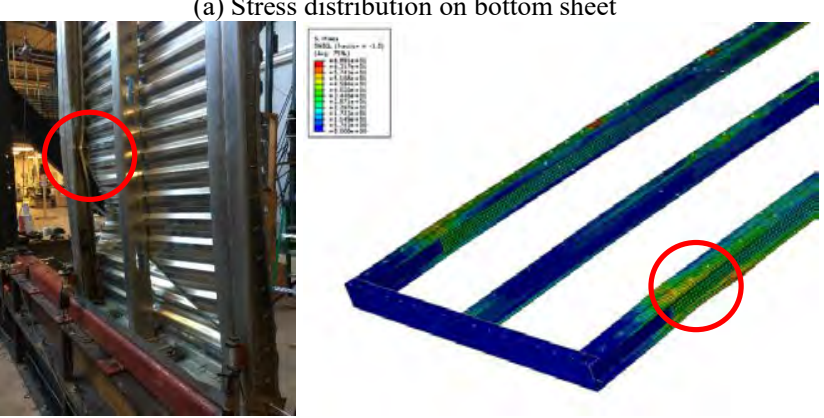

(b) Local and distortional buckling of studs

Figure 13: Failure modes

Table 4: The comparison of test results and Abaqus results

\begin{tabular}{ccccc}
\hline & Pmax $(\mathrm{kN})$ & $\begin{array}{c}\text { Rati } \\
\mathrm{o}\end{array}$ & $\Delta \max (\mathrm{mm})$ & $\begin{array}{c}\text { Rati } \\
\mathrm{o}\end{array}$ \\
\hline Test results & 80.83 & - & 68.4 & - \\
Abaqus results & 80.78 & 1.00 & 59.1 & 0.86 \\
\hline
\end{tabular}




\section{PARAMETRIC ANALYSIS}

\subsection{The influence of framing thickness}

A desired ultimate failure state of CFS shear wall should ensure that the stress of the framing members remains at a relatively low level (elastic stage) while the sheathing buckling occurs. As a result, the adoption of framing thickness is of great importance. The framing thickness in this research included $1.372 \mathrm{~mm}$ (54mil), $1.727 \mathrm{~mm}$ (68mil), and $2.464 \mathrm{~mm}(97 \mathrm{mil})$ and the sheathing thickness remained constant at $0.686 \mathrm{~mm}(27 \mathrm{mil})$ for all tests. The comparison of load vs. displacement curves is shown in Figure 14, from which we can see that there is an increase in shear strength and a decrease in the deflection at peak load as the framing thickness increases. Compared with $1.372 \mathrm{~mm}$ (54mil) framing thickness shear wall, the shear strength of shear walls with $1.727 \mathrm{~mm}$ (68mil) and $2.464 \mathrm{~mm}(97 \mathrm{mil})$ framing thickness improved 3.7\% and 9.0\% respectively. However, the failure modes of $1.372 \mathrm{~mm}(54 \mathrm{mil})$ framing thickness shear wall included sheet buckling as well as stud buckling, as shown in Figure 15.

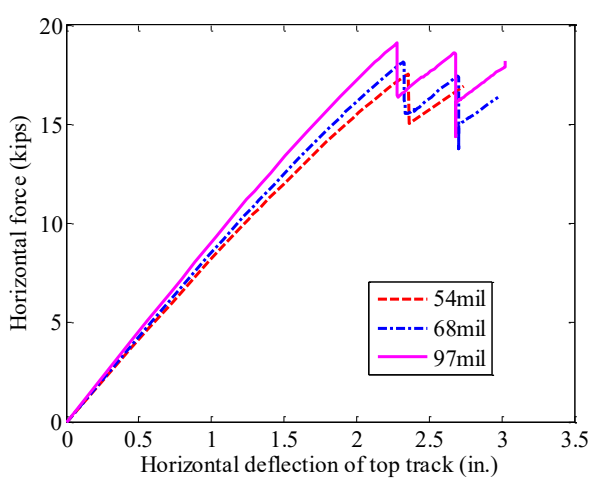

Figure 14: Load deformation responses

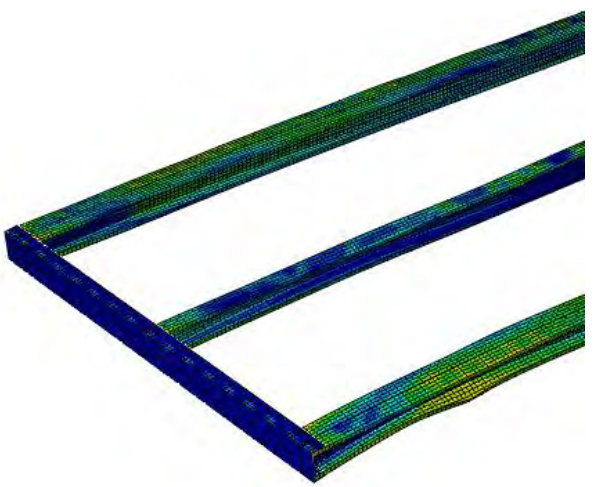

Figure 15: Stud buckling

In conclusion, the influence of framing thickness on shear capacity of corrugated sheet shear walls is really limited. It can also be concluded that when using corrugated steel sheets with $0.686 \mathrm{~mm}(27 \mathrm{mil})$ thickness, the framing members must be of $1.727 \mathrm{~mm}(68 \mathrm{mil})$ or higher thickness to avoid stud buckling and framing failure.

\subsection{The influence of stud cross section}

To explore the influence of stud cross section on the shear capacity of the shear wall, 4 shear wall models with different stud cross sections were simulated, including stud 350S162-68, 362S162-68, and 400S162-68. The framing thickness remained the same and only the height of the stud varied. The load vs. displacement curves are shown in Figure 16 and the comparison of the shear strength is summarized in Table 5. It can be observed that in comparison to 350S162-68 stud framed wall, the differences of the shear capacity and the displacement at peak load are no more than $1 \%$. Therefore, it can be concluded that the stud cross section has little effect on the shear capacity of the corrugated sheet shear walls and can be neglected in future analysis.

Table 5: The influence of stud cross section

\begin{tabular}{ccccc}
\hline $\begin{array}{c}\text { Stud cross } \\
\text { section }\end{array}$ & Pmax $(\mathrm{kN})$ & $\begin{array}{c}\text { Rati } \\
\text { o }\end{array}$ & $\Delta \max (\mathrm{mm})$ & $\begin{array}{c}\text { Rati } \\
\text { o }\end{array}$ \\
\hline 350S162-68 & 80.78 & - & 59.1 & - \\
362S162-68 & 80.87 & 1.00 & 59.2 & 1.00 \\
400S162-68 & 81.80 & 1.01 & 59.5 & 1.01 \\
\hline
\end{tabular}




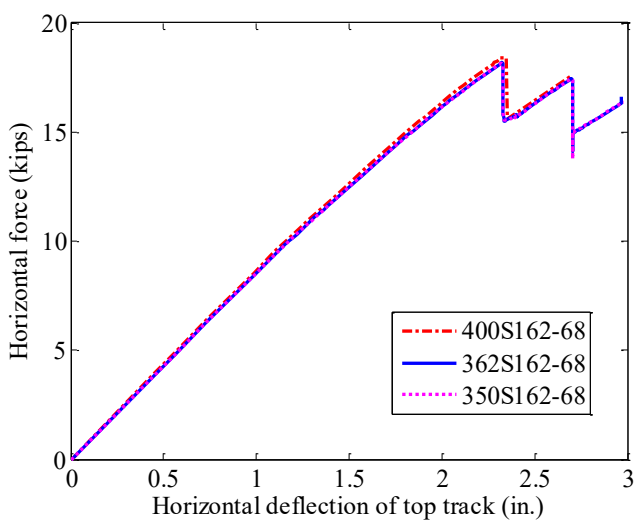

Figure 16: Load deformation responses

\subsection{The influence of framing material properties}

The yield strength of the framing member may affect the shear capacity of the wall. Two shear wall models with different framing material properties were simulated in this paper, including the yield strength of $228 \mathrm{Mpa}(33 \mathrm{ksi})$ and $345 \mathrm{Mpa}(50 \mathrm{ksi})$. The results are shown in Figure 17 and Table 6, from which we can see the shear capacity increased by $4 \%$ and the displacement at peak point postponed by $3 \%$ when the yield strength increased from $228 \mathrm{Mpa}(33 \mathrm{ksi})$ to $345 \mathrm{Mpa}(50 \mathrm{ksi})$. However, stud buckling was also noticed at the failure point in the shear wall model with the lower framing material, as shown in Figure 18. Thus such conclusion can be made: the influence of the yield strength of the frame member on shear capacities of corrugated sheet shear walls is very limited and can be neglected. However, it's recommended that yield strength of the frame member to be $345 \mathrm{Mpa}$ (50 ksi) in order to ensure the strength requirement and to avoid the stud buckling.

Table 6: The influence of framing material

\begin{tabular}{ccccc}
\hline $\begin{array}{c}\text { Material } \\
\text { grade }\end{array}$ & Pmax $(\mathrm{kN})$ & $\begin{array}{c}\text { Rati } \\
\text { o }\end{array}$ & $\Delta \max (\mathrm{mm})$ & $\begin{array}{c}\text { Rati } \\
\mathrm{o}\end{array}$ \\
\hline $227 \mathrm{Mpa}$ & 77.98 & - & 61.0 & - \\
$345 \mathrm{Mpa}$ & 80.78 & 1.04 & 59.1 & 0.97 \\
\hline
\end{tabular}

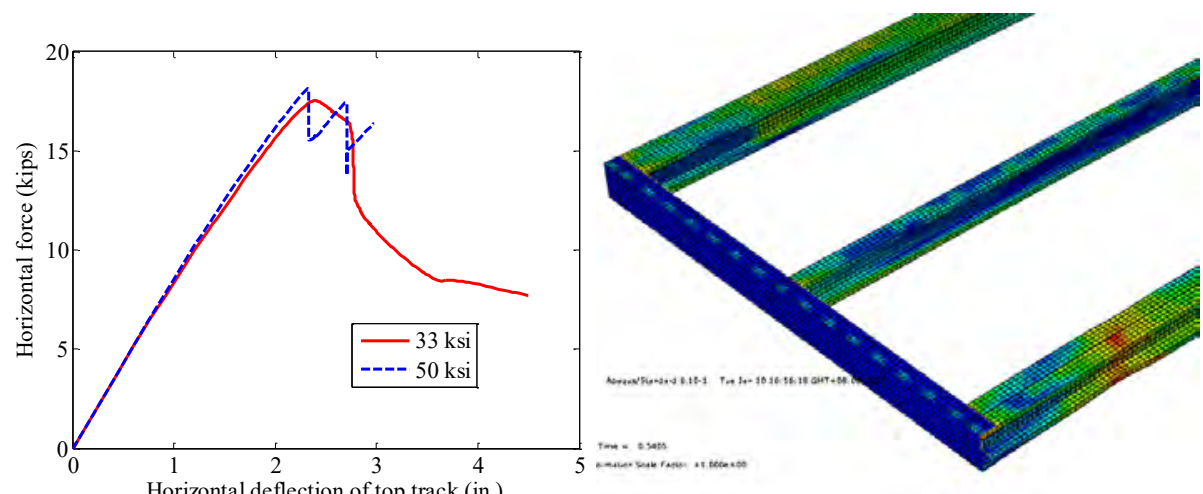

Figure 17: Load deformation responses

Figure 18: Stud buckling 


\subsection{The influence of framing material properties}

Studs are generally spaced between $406 \mathrm{~mm}$ (16 in.) to $610 \mathrm{~mm}$ (24 in.) on center. The influence of stud spacing on shear wall's shear capacity has always been one of the major concerns by researchers and engineers. Two shear wall models with $406 \mathrm{~mm}(16 \mathrm{in}$.) $/ 610 \mathrm{~mm}(24 \mathrm{in}$.) stud spacing were created and compared. The load vs. displacement curves are shown in Figure 19, from which we can see the bearing capacity of shear wall with $406 \mathrm{~mm}$ (16 in.) stud spacing was much higher than shear wall with $610 \mathrm{~mm}$ (24 in.) stud spacing. The reason for this improvement is that the number of screws between the sheathing and the frame has increased with the closer stud spacing. Besides, the displacement at failure point of shear wall with $406 \mathrm{~mm}$ (16 in.) stud spacing postponed from $59.1 \mathrm{~mm}$ (2.329 in.) to $81.1 \mathrm{~mm}$ (3.193 in.). According to ASCE 7-16 (2016) and IBC-15 (2015), the allowable story drift is $1 / 40$ of the story height. The shear strength was calculated consequently and summarized in Table 7 . The results indicated that the shear strength of shear wall with $406 \mathrm{~mm}$ (16 in.) stud spacing was $11 \%$ higher than shear wall with $610 \mathrm{~mm}(24$ in.) stud spacing.

In conclusion, the shear capacity of the corrugated sheet shear wall can be greatly improved with smaller stud spacing. It is suggested that the stud spacing should be no more than 24 in. in building systems.

Table 7: The influence of stud spacing

\begin{tabular}{ccccc}
\hline $\begin{array}{c}\text { Stud } \\
\text { spacing }\end{array}$ & Pmax $(\mathrm{kN})$ & $\begin{array}{c}\text { Rati } \\
\mathrm{o}\end{array}$ & $\Delta \max (\mathrm{mm})$ & $\begin{array}{c}\text { Rati } \\
\mathrm{o}\end{array}$ \\
\hline $610 \mathrm{~mm}$ & 80.78 & - & 59.1 & - \\
$406 \mathrm{~mm}$ & 89.59 & 1.11 & 61.0 & 1.03 \\
\hline
\end{tabular}

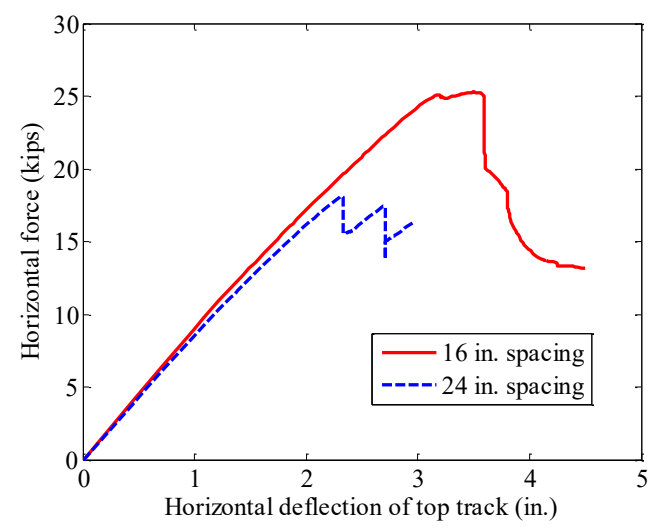

Figure 19: Load deformation responses

\subsection{The influence of gravity/vertical load}

Shear wall models under combined lateral and gravity loading were also analyzed. The gravity load was applied as uniform pressure on the top track. The comparison of the load vs. displacement curves with different loading method are shown in Figure 20, from which we can see these two curves almost coincide with each other. In conclusion: since the gravity/vertical loads of low-rise cold-formed thin-wall steel structure is limited, the influence of vertical loads on shear capacity can be neglected. 


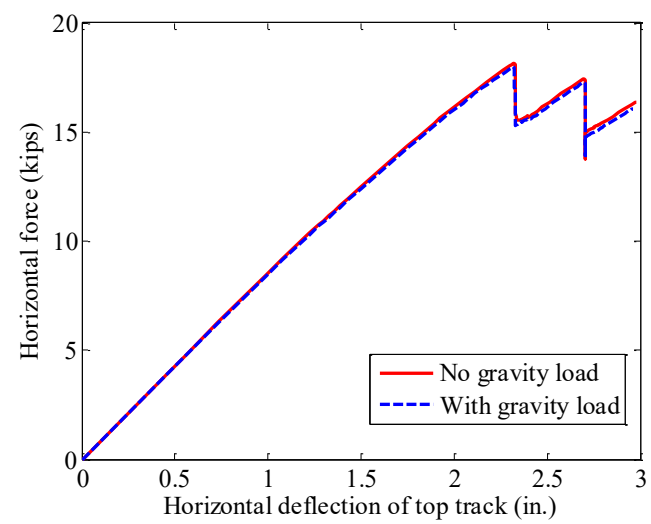

Figure 20: Load deformation responses

\section{CONCLUSION}

CFS shear walls with corrugated steel sheathing were tested under monotonic and cyclic loading. The shear walls yielded an average initial stiffness of $1.95 \mathrm{kN} / \mathrm{mm}$ and shear strength of $66.02 \mathrm{kN} / \mathrm{m}$ (4525 plf) which is considerably higher than the shear strength of $11.1 \mathrm{~mm}(7 / 16 \mathrm{in}$.) OSB and $11.9 \mathrm{~mm}(15 / 32 \mathrm{in}$.) plywood sheathing given in AISI S240 (2015). The test results also indicate that the gravity loads in CFS structures is limited and almost make no difference on the shear walls' shear behavior. The agreement of the FEA results and test results indicates the validity of the modeling technique used in this paper. Some useful conclusions are provided based on the parametric analysis.

\section{ACKNOWLEDGMENTS}

This paper was part of the U.S. National Science Foundation grant, NSF-CMMI-0955189: Comprehensive Research on Cold-Formed Steel Sheathed Shear Walls, Special Detailing, Design, and Innovation. The research was also partially supported by the Chinese National Science Foundation Grant No. 51538002. Any opinions, findings, and conclusions or recommendations expressed in this article are those of the authors and do not necessarily reflect the views of the sponsors.

\section{REFERENCES}

[1] Abaqus (2014). [Computer software]. Version 6.14, Dassault Systèmes, Waltham, MA.

[2] AISI S240 (2015). "North American Standard for Cold-Formed Steel Structural Framing". American Iron and Steel Institute, Washington, D.C.

[3] ASCE 7 (2016). "Minimum design loads for buildings and other structures". Reston, VA: American Society of Civil Engineers.

[4] ASTM A370 (2006). "A370-06 Standard Test Methods and Definitions for Mechanical Testing of Steel Products", American Society for Testing and Materials, West Conshohocken, PA.

[5] ASTM E564 (2012). "Standard Practice for Static Load Test for Shear Resistance of Framed Walls for Buildings", American Society for Testing and Materials, West Conshohocken, PA.

[6] ASTM E2126 (2012). "Standard Test Methods for Cyclic (Reversed) Load Test for Shear Resistance of Vertical Elements of the Lateral Force Resisting Systems for Buildings", American Society of Testing and Materials: West Conshohocken, PA. 
[7] Dai, X. (2012). "Numerical Modelling and Analysis of Structural Behavior of Wall-stud Coldformed Steel Shear Wall Panels under In-plane Monotonic Loads." Journal of Civil Engineering Research, 2(5), 31-41.

[8] Fülöp and Dubina. (2004). "Performance of wall-stud cold-formed shear panels under monotonic and cyclic loading Part I: Experimental research", Thin-Walled Structures, 42, 321-338.

[9] IBC (2012). "International Building Code, 2012 Edition”, International Code Council, Washington, DC.

[10] Madsen, R.L., Nakata, N., Schafer, B.W. (2011). "CFS-NEES Building Structural Design Narrative". www.ce.jhu.edu/cfsness.

[11] Mahdavian, M., Zhang, W., Ding, C., Moen, C., and Yu, C. (2016). "Cyclic Simulation of ColdFormed Steel Shear Walls with Corrugated Steel Sheathing." Proceedings of the Annual Stability Conference, Orlando, Florida.

[12] Ngo, H.H. (2014). "Numerical and Experimental Studies of Wood Sheathed Cold-Formed Steel Framed Shear Walls." Masters of Science in Engineering, Johns Hopkins University, Baltimore, Maryland.

[13] SSMA. (2015). Steel Stud Manufacturers Association product technical guide.

[14] Stojadinovic and Tipping. (2007), "Structural testing of corrugated sheet steel shear walls." Report submitted to Charles Pankow Foundation, Ontario, CA.

[15] Yu, C., Huang, Z., Vora, H. (2009). "Cold-Formed Steel Framed Shear Wall Assemblies with Corrugated Sheet Steel Sheathing", Proceedings of the Annual Stability Conference, Structural Stability Research Council, Phoenix, AZ, April 2009.

[16] Yu, G. (2013). "Cold-Formed Steel Framed Shear Wall Sheathed with Corrugated Steel Sheet", Master Thesis, University of North Texas. 